\title{
A MARCHA DO "CAPITALISMO UNIVERSITÁRIO" NO BRASIL NOS ANOS $1990^{1}$
}

\author{
André Luiz de Miranda Martins* \\ Recebido em: 24 de julho de 2008 \\ Aprovado em: 14 de setembro de 2008 \\ *Doutor em Economia Aplicada, Professor Adjunto da Universidade Federal de Pernambuco (Centro Aca- \\ dêmico do Agreste, Caruaru-PE). E-mail: andremartins@ufpe.br.
}

Resumo: O seguinte artigo analisa a consolidação dos modelos de "fábrica de conhecimentos" e de "capitalismo universitário" no Brasil na década de 1990, sob a égide da crítica neoliberal à gestão pública da educação pós-secundária. Após uma breve menção a esses modelos, discute o crescimento das instituições de ensino superior privado organizadas como empresas lucrativas e a redefinição institucional da universidade pública, que se aproxima do modelo de gestão daquelas instituições. Em sua conclusão, nota-se que um dos maiores danos provocados pela disseminação das práticas derivadas daqueles modelos é a lenta corrosão do papel de referente cultural da Universidade; e são apontados temas para futuras pesquisas.

Palavras-chave: Universidade. Capitalismo universitário. Ensino superior privado.

THE MARCH OF “ACADEMIC CAPITALISM” IN BRAZIL DURING THE 1990S.

Abstract: The following paper assesses the consolidation of the "knowledge factory" and "academic capitalism" models in Brazil during the 1990s, under the aegis of the neoliberal critique of public, post-secondary education management. After a brief mention to these models, it discusses the growth of private-owned higher education institutions organized as business enterprises, and the institutional redefinition of public universities. As a conclusion, it is pointed out that one of the greater damages brought by the dissemination of such models is the slow corrosion of the role of cultural reference played by the University; and, also, some topics for future research are brought forward.

Key words: University. Academic capitalism. Private-owned higher learning.

\section{Introdução}

Enquanto o pragmatismo neoliberal em avanço na América do Sul - seguindo a via pavimentada pela tecnocracia entronizada durante as ditaduras militares no subcontinente - recomenda, através de suas agências especializadas, que o conjunto das Instituições de Ensino Superior - IES deve reger-se por critérios

$1 \mathrm{O}$ que segue é uma versão modificada da comunicação "Da endogenia defensiva à exogenia imposta: o avanço do "capitalismo universitário" no Brasil e na Argentina na década de 1990", apresentada no VI Encontro Internacional do Fórum Universitário do Mercosul - Fomerco (Aracaju, setembro de 2007). 
de eficiência econômica, e que o financiamento público da educação pós-secundária gratuita pode ser um luxo dispendioso, aumenta a cautela no mundo acadêmico.

A cautela é justificada porquanto remete ao questionamento da possibilidade de se acatar tais recomendações sem que se descuide da condução dos grandes debates culturais - no resguardo dos valores humanísticos -, da difusão de conhecimentos resultante de pesquisa acadêmica, da co-participação no processo de desenvolvimento econômico, da aproximação com a comunidade não-acadêmica (extensão), bem como da formação de profissionais com senso crítico. Sendo esses os fins alegadamente perseguidos pelas universidades públicas e privadas tradicionais. Ainda que sejam de natureza administrativa diferente, ambas as categorias partilham de fins semelhantes, vale dizer.

O que, em geral, não se aplica às IES privadas (faculdades, tipicamente) organizadas como empresa lucrativa. De funcionamento relativamente recente, beneficiadas por nova moldura normativa, já adentraram o cenário da educação superior adequadas aos referidos critérios. Seus fins são funcionais a uma demanda por força de trabalho cada vez mais especializada, que forma o público-alvo preferencial de suas estratégias de marketing. Sua participação na criação de conhecimento novo, isto é, na pesquisa, é inexpressiva; pelo contrário, apropria-se do conhecimento existente, que replica. Seus programas de extensão universitária são, não raro, propagandísticos. Contudo, parece angariar crescente simpatia enquanto aumentam as matrículas nos cursos que oferece. Por fim, é (ao menos parcialmente) auto-financiada, para a alegria da concepção de tesouraria que impera na administração pública brasileira.

O caso brasileiro é aqui exemplar: a duas primeiras categorias, especialmente a universidade pública, atingem sua maturidade na presente década. Nunca se formaram tantos doutores. Nunca o País foi tão citado em periódicos de indexação internacional ${ }^{2}$. Em processo recém iniciado, muitas universidades federais se interiorizaram, isto é, abriram novos campi fora das capitais, onde tradicionalmente se instalaram (esse processo foi sentido com mais força nas regiões economicamente mais débeis, caso do Nordeste, por exemplo). Mas nada disso obsta que se siga rotulando-a de formadora de elites - acadêmicas, técnico-científicas, tecnocráticas, intelectuais. Esse é um dos argumentos da crítica de cunho privatista ao financiamento público do ensino superior: a concentração de renda estaria espelhada no perfil sócio-econômico médio dos

2 Dados do Instituto de Estudos Avançados da USP indicam que mais de $90 \%$ das publicações científicas no exterior são de pesquisadores empregados em instituições públicas. 
graduandos em universidades públicas (especialmente nas mais conceituadas), com o ensino pós-secundário gratuito promovendo essa desigualdade.

A couraça da endogenia - a Universidade pública voltada para si -, apenas arranhada pela expansão dos programas de extensão universitária, havida a partir dos anos 1970 como resposta ao crescimento da universidade de massas, mostra hoje a sua face. $\mathrm{O}$ argumento da oferta de ensino superior gratuito esvai-se na dificuldade de acesso, originada na concentração da renda e no descaso com o ensino fundamental e médio gratuitos.

Das IES organizadas como empresas lucrativas, diz-se que se valem de processos seletivos pouco criteriosos no que respeita ao mérito ou bagagem educacional dos "vestibulandos". Aqui vale mais, ou vale na mesma medida, sua capacidade de pagamento. No entanto, têm promovido o acesso das "massas" a um ensino superior cuja qualidade pode ser questionada, mas que certamente faculta aos seus diplomados a busca por uma posição relativamente melhor remunerada em uma dada estrutura de ocupações, com tal remuneração não raro determinada por vias institucionais. A crise do emprego formal dos anos de 1990 - fazendo emergir o argumento da "empregabilidade" - reforçou esse modelo de ensino, dito voltado para o mercado de trabalho. Nessa dimensão instrumental-adaptativa (ou seja, a do adaptar-se às novas exigências de atributos feitas pelos demandantes de trabalho) a "empregabilidade" corresponde à perspectiva das empresas, como observa Silva (2003). No Brasil esse conceito ou representação do trabalho parece ganhar força à medida que se estreita 0 mercado de trabalho formal, processo que se acelerou ao longo da década de 1990.

Um dos argumentos fortes da crítica neoliberal à gestão educacional como política de Estado remete à necessidade de sua despolitização e privatização. Essa necessidade se impõe, segundo seus defensores, com muito mais força quando o objeto da gestão educacional é a educação pós-secundária. Dado que "a possibilidade de combinar qualidade e quantidade com critérios igualitários e universais é uma falsa promessa dos estados interventores e populistas", é preciso "transferir a educação da esfera da política para a esfera do mercado" (GENTILI, 1998, p. 18-9). O argumento não deixa de ser curioso, quando tomado em seu contexto histórico: não foi precisamente o intervencionismo econômico manu militari que há cerca de duas décadas entronizou certo tecnicismo produtivista, que informa que as políticas públicas de Educação devem adequar-se, ao longo de todo o seu ciclo, aos critérios que regem os investimentos? 
Se os argumentos até agora apresentados se guiaram pela máxima weberiana segundo a qual "exagerar é minha profissão", é porque a polarização que se procurou fazer remete à urgência em se buscar um meio-termo diferente do correntemente adotado, que aproxima a Universidade pública do modelo de gestão privado. Ou seja, se, ante a globalização, novos arranjos público-privados na condução do ensino superior precisam ser concebidos, que o seja de modo a promover "concessões" de ambos os lados, na observância das transformações experimentadas pelo mundo do trabalho, mas, também, na concepção de formas de financiamento que preservem a pesquisa acadêmica e a presença da academia nos grandes debates nacionais - mantendo-a, assim, na sua posição de referente cultural. Isso é bem diferente da mera capitulação aos ditames de modelos como de "capitalismo universitário" e de "fábrica de conhecimentos", que parecem avançar incontinenti.

O que segue trata de algumas das evidências do avanço desses modelos no Brasil ao longo da década de 1990. O texto valeu-se da bibliografia pertinente ao assunto e de bases de dados de educação superior, do Inep/MEC, e de mercado de trabalho, do DIEESE.

\section{Da "Fábrica de Conhecimentos" ao "Capitalismo Universitário"}

Ambos os modelos acenam para a conversão da universidade como instituição para a universidade como organização e chancelam a primazia do mercado para definir os usos da educação superior. A "fábrica de conhecimentos" concebe um ensino superior com a finalidade primordial de fornecer aos seus "consumidores" as destrezas necessárias ao ingresso (ou, não, raro, reingresso) no mundo de trabalho, de preferência naquelas ocupações atualmente mais valorizadas pelo mercado. À base de uma leitura algo canhestra das conclusões das teorias do capital humano e, sem dúvida, de estratégias agressivas de marketing, dissemina-se a idéia segundo a qual a formação para o mercado de trabalho é tão-somente a formação específica para o desempenho de determinada atividade - ou, por outros termos, o investimento (sim, pois aqui se tratam de relações mercantis) em educação que apresenta os retornos mais eficientes. Formação corporativa ou técnica para um mundo corporativo e tecnificado.

Estamos aqui no território dos cursos seriados e de curta duração, das faculdades corporativas, da pos-graduação "profissionalizante", em que predomina a oferta de cursos de "gestão" - curiosamente oposta ou suplementar à administração de empresas -, comércio exterior, design para informática, "sistemas de 
informação", perícia, entre outras atividades desempenhadas tipicamente pelos subprofissionais de uma indústria tecnocientífica crescentemente volátil. Fica para a Economia traçar um cenário em que a demanda por essa mão-de-obra especializada aumentará o suficiente para atingir o equilíbrio com uma oferta que não dá indícios de diminuir suas taxas de crescimento.

Tomamos por empréstimo o termo "fábrica de conhecimentos" [knowledge factory], usado em Aronowitz (2000) cientes de que o fenômeno analisado por este autor expressa mais fielmente a realidade institucional da universidade dos EUA. Informa-nos este autor que o termo foi originalmente formulado nos anos 1960 por Clark Kerr, especialista em relações industriais e então reitor da Universidade da Califórnia em Berkeley. Em seu muito influente The uses of the university, de 1963, Kerr formularia as premissas essenciais para o papel da universidade, alertando para a então urgente percepção institucional de que "o produto invisível da universidade, o conhecimento, pode ser o componente mais poderoso de nossa cultura, influenciando a ascensão e queda das profissões e mesmo das classes sociais, regiões e nações" (apud ARONOWITZ, op. cit, p. 30; tradução nossa).

Kerr pregava a organização do sistema universitário estadunidense em dois grupos: um em que a pós-graduação e a graduação seriam devotadas a áreas científico-tecnológicas, com ênfase em pesquisa aplicada; e outro reservado para o treinamento e formação de nível superior de mão-de-obra para áreas técnicas. Na realidade brasileira, "fábrica de conhecimentos" aproxima-se mais do pejorativo "fábrica de diplomas", popularizado a partir dos anos de 1970 com a massificação do ensino universitário.

$\mathrm{Na}$ verdade, a "fábrica de conhecimentos", em sua versão brasileira, é uma expressão mais, digamos, rasteira de um "capitalismo universitário" de disseminação mais sutil. O termo foi cunhado por Slaughter e Leslie (1997), a partir da constatação, nos marcos da globalização, do "desenvolvimento de políticas nacionais centradas na pesquisa aplicada e na inovação, na redução do montante de subsídios diretos do Estado às instituições e o incremento dos vínculos dos acadêmicos com o mercado". (IBARRA COLADO, 2003, p. 1059; tradução nossa).

Os autores sublinham que a universidade dispõe de um único ativo, o capital humano de seus professores e/ ou pesquisadores. O capitalismo acadêmico referir-se-ia, assim, a um conjunto de iniciativas e comportamentos economicamente motivados para incrementar a captação de recursos externos a partir deste estoque específico de capital. 


\section{O Avanço do Ensino Privado}

No Brasil dos anos 1990, a inserção efetiva nos circuitos econômicos globais, transformando o desemprego em fenômeno estrutural, fez dessa variável macroeconômica um dos alvos preferenciais das políticas públicas de mercado de trabalho e formação profissional - concebida prioritariamente para garantir o ingresso do trabalhador brasileiro no contexto da reestruturação produtiva em curso. À base dessa concepção, tinha-se como certa a indispensabilidade da formação de mão-de-obra de nível superior, a empregar-se em um setor de serviços moderno (o "terciário moderno") em expansão e crescentemente conectado à economia global.

Datando do mesmo período as políticas de reforma gerencial da administração pública e de privatização do setor produtivo estatal e dos serviços de utilidade pública, tudo parecia indicar que a tarefa de levar adiante esses processos formativos caberia, com efeito, ao setor privado. A reforma institucional do ensino superior, materializada na Lei de Diretrizes e Bases da Educação Nacional-LDB, de 1996, insipirada no ideário da reforma do Estado e, principalmente, nas diretrizes do Banco Mundial e da UNESCO, "relidas" no âmbito do MEC, chancelaria essa preferência.

Estas foram divulgadas em La enseñanza superior: las lecciones derivadas de la experiência, documento do Banco Mundial, de 1995; no "Relatório Delors", da Unesco, de 2001, e no Planejamento Político-Estratégico 1995/1998, do MEC. Tanto os documentos do Banco Mundial e da Unesco quanto o do MEC coincidem em que a reforma da educação superior no Brasil, então em discussão, deveria pautar-se pela defesa dos pilares da educação institucional e da diversificação do ensino. Viabilizando, consequentemente, como observa Minto (2006, p. 159),

a quebra do 'modelo único' de ensino superior, com a proliferação, sobretudo, dos cursos de formação rápida e do ensino à distância; pelo diagnóstico das dificuldades de investir em educação e a necessidade de buscar saídas, principalmente nas parcerias com o setor privado; por uma concepção de autonomia universitária tal que ultrapasse o confronto entre a lógica do serviço público e a do mercado de trabalho, adequando-se às formas de financiamento misto (público e privado).

Os mesmos documentos ressaltam também a necessidade de se avaliar a educação superior a partir de critérios de eficiência, qualidade e equidade, convertíveis em prestação de contas à sociedade. 
É possível identificar a disseminação no capitalismo universitário, por exemplo, no crescimento vertiginoso do "novo ensino superior privado" - que não deve confundir-se com as IES privadas comunitárias e confessionais -, "de perfil laico [...], comandado por uma lógica de mercado e um acentuado ethos empresarial" (MARTINS, 2000, p. 46), surgido no final dos anos de 1960 e em expansão mais acelerada na década seguinte.

Mas a década do ensino superior privado por excelência haveria de ser, com efeito, a de 1990, com a fundamental contribuição das mudanças no marco regulatório pertinente ${ }^{3}$. Despontam aqui as universidades particulares do segmento do novo ensino privado que apresentaram um crescimento de $90 \%$ entre 1990 e 1998 (8,35\% ao ano). O fato deste crescimento ter sido influenciado, como sugere Martins (p. 46), "pela fusão de estabelecimentos isolados, que decresceram durante esse período, e/ou pela criação de faculdades integradas particulares, as quais funcionaram como uma espécie de incubadora de novas universidades", evidencia o papel do novo conjunto de regulações.

Consolidada a participação expressiva do setor privado tanto no conjunto das IES brasileiras - beirando os 80\% em 1998 -, e prevalecendo, pois, a lógica do mercado, o salto qualitativo que se verificou é marcado pela ascensão à natureza universitária de muitas faculdades privadas, sob a égide de um modelo que continua referenciado pela Universidade como instituição, em que são indissociáveis as atividades de ensino, pesquisa e extensão. Ascensão problemática! Como observa Martins (p. 46-7),

a expansão recente das universidades particulares foi conduzida pelo interesse de suas mantenedoras em obter maior autonomia, conferida legalmente a esse tipo de instituição, principalmente a liberdade de expandir seus cursos e ampliar as vagas existentes. Expressa também uma estratégia, direta ou indireta, de maximizar simbolicamente a posição dessas instituições no interior do campo acadêmico vis-à-vis com estabelecimentos não-universitários, procurando demarcar posições e aumentar a rentabilidade simbólica de seus títulos escolares nos mercados acadêmico e extra-acadêmico. Várias dessas novas instituições $[\ldots]$ enfrentam sérias atividades no seu cotidiano para implantar uma sólida carreira docente, e não têm obtido resultados convincentes na institucionalização da prática da pesquisa científica e na montagem de seus cursos de pós-graduação [...]. Muitas delas, com vocação estrutural para as atividades de ensino, criam uma série de artificialismos acadêmicos para atender às exigências $[. .$. da legislação.

3 Cabe mencionar, além da LDB, de 1996, o Decreto n 3.860, de 2001, que definiu as IES não-universitárias: centros universitários, faculdades integradas e institutos superiores. 
Legal e simbolicamente Universidades, IES organizadas como empresas lucrativas não logram (ou não se ocupam de) atender os requisitos acadêmicos cobrados à condição alçada. Vale frisar que fazê-lo não raro iria contra sua própria lógica econômica, especialmente no requisito de produção científica resultante de pesquisas. Por outro lado, essa lógica mesma assegura com que preencham, ancoradas em estratégias agressivas de marketing, um certo "vazio" alegadamente deixado pelas universidades públicas: o da formação profissional voltada à demanda de força de trabalho especializada.

Formação de mão-de-obra qualificada e dotada das "competências" necessárias à disputa por vagas no mercado de trabalho à parte, é certo que essa expansão foi suficiente para transformar o mercado de trabalho específico para a educação superior, como ilustra a tabela 1 abaixo. Notem-se as excepcionais taxas de crescimento das ocupações de docente e funcionário.

Tabela 1 - Evolução da ocupação no ensino superior privado no Brasil, 1994-2001

\begin{tabular}{lrrr}
\hline Categorias ocupacionais & $\mathbf{1 9 9 4}$ & $\mathbf{2 0 0 1}$ & \multicolumn{1}{c}{$\mathbf{2 0 0 1 / 1 9 9 4}$} \\
\hline Docentes & 48.980 & 128.997 & $163,4 \%$ (12,8\% a.a.) \\
Mestres & 7.166 & 45.532 & 535,4 (26\% a.a.) \\
Doutores & 2.376 & 15.278 & 543,0 ( $26,2 \%$ a.a.) \\
Funcionários & 24.371 & 99.739 & 309,2 (19,2\% a.a.) \\
\hline
\end{tabular}

Fonte: DIEESE (2002).

Os índices de crescimento de doutores ocupados na docência ao longo do período citado no setor privado tornam-se particularmente preocupantes quando se nota que a pós-graduação, lócus de sua formação, está quase toda concentrada nas IES públicas, federais e estaduais, sendo em larga medida ofertada com financiamento público. E que, apesar da política indutiva, orientada e conduzida pelo governo federal, de expansão da pós-graduação, parece estar em curso um "vazamento" de doutores para o ensino superior privado.

Por exemplo, a partir de dados disponíveis em Martins (p. 54), tem-se que, em 1998, de todos os doutores exercendo a docência no Brasil, cerca de $20 \%$ deles se encontravam em IES privadas, majoritariamente em universidades privadas. Ainda que entre 1998 e 2001 a taxa de expansão destas (essencialmente do "novo ensino superior privado", como já se sublinhou) tenha arrefecido, 
compreende-se o salto de doutores contratados como docentes do setor privado observado nesse interregno, registrado à tabela 1, porquanto essa titulação específica tem crescido a taxas impressionantes. No ano de 1987, a formação de doutores ultrapassou a marca dos mil titulados, crescendo $12 \%$ ao ano até 1998 (MARTINS, p. 54). Se, com efeito, impressiona que entre 1998 e 2001 tenha dobrado o contingente de doutores contratados com docentes por IES privadas (universidades e outras), numa expansão de 19,35\% ao ano, cabe lembrar que foi precisamente nesse interregno que há de ter maturado um certo "efeito-LDB", expresso na expansão das IES privadas facultado pelo novo marco regulatório.

\section{A Redefinição Institucional da Universidade Pública}

Seria insuficiente o registro, à busca de causas do mencionado "vazamento", a insuficiência de recursos orçamentários a alocar-se na pós-graduação - faltam investimentos, mas, mesmo assim, já se dispõe de centros de excelência e cresce o número de centros de pós-graduação beneficiados por um fluxo constante de recursos das agências de fomento à pesquisa. Tampouco seria suficiente, para este fim, notar a falta de políticas de colocação de recém-doutores sem vínculo acadêmico-institucional anterior à sua titulação. Se a expansão/ interiorização das redes federal e estadual é apenas um paliativo, expandir eficientemente, de modo a acomodar a oferta de pesquisadores - na medida em que é o doutorado que os forma - requereria uma revisão estatutária de execução impossível no curto e no médio prazo, levantando discussões que não se pode conduzir aqui.

É preciso constatar, com a devida gravidade, a brutal transferência de renda do setor público para o setor privado, havida em conseqüência desse "vazamento": IES organizadas como empresas lucrativas contratam profissionais acadêmicos que concluíram sua formação - via de regra, em IES públicas -, não carecendo de neles investir um cobre a mais do que o esforço social do qual teriam supostamente participado como contribuintes ${ }^{4}$. Até onde sabemos, a medida dessa transferência de renda segue por estudar.

Transferência de renda, de capital simbólico e humano para o ensino superior organizado por princípios mercantis... Nesse compasso a universidade pública mesma se transforma, assimilando princípios de organização eficiente e se

4 No caso dos profissionais acadêmicos com título de mestre, parece ter-se formado um círculo vicioso de difícil quebra: dar prosseguimento à carreira acadêmica significa, para muitos deles, o reingresso em um sistema em que a oferta de vagas para doutorado excede a cobertura (bolsas) assegurada pelas agências de fomento (via bolsas de estudo ou de pesquisa) - com o que a busca por financiamento recairá no plano individual e passará muito frequentemente pela "venda de força de trabalho" às IES privadas. 
redefinindo como player no mercado acadêmico característico do capitalismo universitário. Como explicar, por exemplo, as mudanças nas formas de financiamento da educação superior pública, materializadas na abertura cada vez mais freqüente de cursos de pós-graduação de senso estrito e de curta duração, cujo custeio recai no aluno? A competição por alunos à base de um capital simbólico acumulado num tempo histórico outro, em que as instituições universitárias públicas fechavam-se para o "mercado", é um claro sinal de transição, ou de adaptação, para a qual concorrem diferentes processos. Silva (2006, p. 293) identifica os seguintes:

heteronomia (absorção de critérios extrínsecos como paradigmas do modo de ser, da organização e gestão da Universidade), a privatização (assimilação dos mecanismos neoliberais de destruição da esfera pública) e subordinação ao mercado (entronização de critérios ligados ao tecnocratismo economicista). Tais exemplos configuram o quadro da adaptação, que seria ao mesmo tempo o abandono do perfil institucional em prol do perfil organizacional.

\section{Considerações Finais}

No Brasil, termos como "diferenciação" e "diversificação", referidos aos rumos das instituições de ensino superior a partir dos anos de 1990, têm ocupado espaço relevante. E a forte carga de tecnicismo que os aponta como eixos de um processo de adaptação que fará prevalecer a (supostamente) preferida lógica do mercado na oferta de educação pós-secundária tem logrado, em ambos os países, desvia a atenção para aquele que é, sem dúvida, o maior dano provocado pela entronização das práticas do capitalismo universitário: a lenta corrosão do papel de referente cultural da Universidade. Aqui a "diferenciação institucional" materializa-se em "convergência institucional".

Espera-se que este artigo tenha indicado temas para futuras pesquisas. Quais sejam: as relações entre graduação e pós-graduação e mercado de trabalho; o protagonismo do setor privado no campo da educação superior; o financiamento do ensino nas universidades públicas; e que, a partir deles, se possa dar início a uma discussão ampla sobre a emergência do Estado Avaliador, e seu impacto sobre a autonomia universitária. 


\section{Referências}

ARONOWITZ, Stanley. The knowledge factory: dismantling the corporate university and creating true higher learning. Boston: Beacon, 2000.

DIEESE. Estatísticas da educação superior. Porto Alegre: DIEESE - Subseção FETEE-SUL, nov. 2002.

GENTILI, Pablo. A falsificação do consenso: simulacro e imposição na reforma educacional do neoliberalismo. 3. ed. Petrópolis, RJ: Vozes, 1998. IBARRA COLADO, Eduardo. Capitalismo académico y globalización: la universidad reinventada. Educação e Sociedade, Campinas, SP, v. 24, n. 84, p. 1059-1067, set. 2003.

MARTINS, Carlos B. O ensino superior brasileiro nos anos 90. São Paulo em perspectiva, São Paulo, v. 14, n. 1, p. 41-60, jan./mar. 2000,

MINTO, Lalo W. As reformas do ensino superior no Brasil: o público e o privado em questão. Campinas, SP: Autores Associados, 2006.

SILVA, Franklin L. Universidade: a idéia e a história. In: STEINER, João E.; MALNIC, Gerhard (Orgs.). Ensino superior: conceito e dinâmica. São Paulo: Edusp, 2006. p. 285-296.

SILVA, Luiz A. M. Mercado de trabalho, ontem e hoje: informalidade e empregabilidade como categorias de entendimento. In: SANTANA. Marco A.; RAMALHO, José R. Além da fábrica: trabalhadores, sindicatos e a nova questão social. São Paulo: Boitempo, 2003. p. 140-178.

SLAUGHTER, Sheila; LESLIE, Larry L. Academic capitalism: politics, policies and the entrepreneurial university. Baltimore: Johns Hopkins, 1997. 